Article

\title{
Texture and Stress Evolution in HfN Films Sputter-Deposited at Oblique Angles
}

\author{
Grégory Abadias ${ }^{1, *}$, Frrat Anğay ${ }^{1}$, Rubenson Mareus ${ }^{1,2}$ and Cédric Mastail ${ }^{1}$ \\ 1 Institut Pprime, Département Physique et Mécanique des Matériaux, Université de Poitiers-CNRS-ENSMA, \\ SP2MI, Téléport 2, 86962 Futuroscope-Chasseneuil, France \\ 2 Département Physique, Université d'Etat d'Haïti-Ecole Normale Supérieure, Laboratoire des Sciences pour \\ l'Environnement et l'Energie (LS2E), HT6115 Canapé-Vert, Port-au-Prince, Haiti \\ * Correspondence: gregory.abadias@univ-poitiers.fr
}

Received: 17 September 2019; Accepted: 29 October 2019; Published: 31 October 2019

check for updates

\begin{abstract}
In this study, polycrystalline hafnium nitride (HfN) thin films were grown by oblique angle deposition (OAD) technique to investigate the relationship between column tilt angle, texture development and residual stress evolution with varying inclination angle $\alpha$ of the substrate. The films ( $\sim 1 \mu \mathrm{m}$ thickness) were grown at various angles $\left(\alpha=5^{\circ}, 25^{\circ}, 35^{\circ}, 65^{\circ}, 75^{\circ}\right.$, and $\left.85^{\circ}\right)$ with respect to the substrate normal by reactive magnetron sputtering at $0.3 \mathrm{~Pa}$ and $300^{\circ} \mathrm{C}$. The film morphology, crystal structure and residual stress state were characterized by scanning electron microscopy and X-ray diffraction (XRD), including pole figure and $\sin ^{2} \psi$ measurements. All HfN films had a cubic, $\mathrm{NaCl}$-type crystal structure with an [111] out-of-plane orientation and exhibited a biaxial texture for $\alpha \geq 35^{\circ}$. XRD pole figures reveal that the crystal habit of the grains consists of $\{100\}$ facets constituting triangular-base pyramids, with a side and a corner facing the projection of the incoming particle flux (indicative of a double in-plane alignment). A columnar microstructure was formed for $\alpha \geq 35^{\circ}$, with typical column widths of $100 \mathrm{~nm}$. It is observed that the column tilt angle $\beta$ increases monotonously for $\alpha \geq 35^{\circ}$, reaching $\beta=34^{\circ}$ at $\alpha=85^{\circ}$. This variation at microscopic scale is correlated with the tilt angle of the (111) crystallographic planes, changing from -24.8 to $11.3^{\circ}$ with respect to the substrate surface. The residual stress changes from strongly compressive $\left(\sim-5 \mathrm{GPa}\right.$ at $\left.\alpha=5^{\circ}\right)$ to negligible or slightly tensile for $\alpha \geq 35^{\circ}$. The observed trends are compared to previous works of the literature and discussed based on existing crystal growth and stress models, as well as in light of energy and angular distribution of the incident particle flux calculated by Monte Carlo. Importantly, a decrease of the average kinetic energy of $\mathrm{Hf}$ particles from 22.4 to $17.7 \mathrm{eV}$ is found with increasing $\alpha$ due to an increase number of collisions.
\end{abstract}

Keywords: glancing angle deposition (GLAD); HfN; columnar growth; biaxial texture; stress

\section{Introduction}

The physical vapor deposition of thin films at off-normal conditions is a simple and effective way to engineer the growth morphology of the films on the micro- and nano-scale and entail specific physical properties [1]. These techniques, known as oblique angle deposition (OAD) or glancing angle deposition (GLAD) when the substrate faces the incoming vapor flux at shallow angles, have become popular over the last decades [2-4]. By implementing such geometrical configurations, films with slanted columnar structure and porous morphology can be achieved, which are of technological relevance in various fields, such as sensor technology, electronic and photonic applications, catalysis, energy harvesting and storage [4]. By monitoring substrate motion, films with controlled nano-architectures and sculptured profiles (nanorods, zig-zags, or spiral shapes) can be additionally tailored $[3,5]$. 
Most studies on films produced with obliquely incident vapor flux have concerned metals and oxides [4], which were primarily synthesized at low temperature and low deposited energy (typically by thermal and electron beam evaporation) to benefit from exacerbated shadowing effects [6]. Combining oblique angle geometries and sputter-deposition technique provides additional degree of freedom to adjust the film morphological features (porosity and column tilt angle) and stoichiometry by varying the deposition pressure or target power [7-11] and employing more than one material source [12-15]. However, studies on transition metal nitride (TMN) films produced at OAD or GLAD conditions remain relatively underexplored [16-21]. Long-used as protective hard coatings, for which achieving a dense and compact microstructure is a pre-requisite, TMN are foreseen as promising candidate materials for plasmonic and sensing applications [22-24]. Therefore, their synthesis by OAD offers an alternative bottom-up route of technological interest to produce nanoparticles or nanostructured layers with enhanced specific surface area or engineerable chiral properties [25].

Besides control of column tilt angle and degree of porosity, the obtention of films with a specific out-of-plane orientation, as well as in-plane alignment [26,27], is of prime importance for most applications as crystallographic texture plays an important role in the materials' properties. However, the development of texture in OAD films, and the link with the column tilt angle, is not fully understood. Moreover, the stress state in these inclined columnar structures is seldom investigated. The present work aims at contributing to a fundamental understanding on how growth morphology, texture development, and stress evolve in sputter-deposited HfN films under obliquely vapor fluxes. HfN, with cubic crystal structure, was chosen as an archetype system to explore these correlations, capitalizing on its ability to develop competitive columnar growth at low-mobility deposition conditions, and as a testing ground for in-plane orientation selection model proposed previously for isostructural TiN films $[16,26]$. Besides, HfN is a conductive and highly reflective (in the visible and IR range) ceramic compound which has potential for use in optoelectronic devices [28] and for plasmonic applications at high temperatures [22,29].

\section{Materials and Methods}

\subsection{Thin Film Preparation at $O A D$ Conditions}

Thin films of HfN were deposited at $300^{\circ} \mathrm{C}$ on (001) Si substrates (size $2.5 \mathrm{~cm} \times 1 \mathrm{~cm}$ ) by direct current reactive magnetron sputtering at different substrate inclination angle $\alpha$ of $5^{\circ}, 25^{\circ}, 35^{\circ}, 65^{\circ}$, $75^{\circ}$, and $85^{\circ}$ with respect to the target (cathode) material. The Hf target was a $75 \mathrm{~mm}$ diameter metallic disk of pure hafnium (purity $99.9 \%$ ), located at $18 \mathrm{~cm}$ from the substrate holder in a confocal configuration, and making a fixed angle of $25^{\circ}$ with respect to the vertical axis of the chamber. More details about the deposition chamber and substrate holder configurations can be found in Reference [21]. Sputter-deposition was operated at constant power (300 W) in an $\mathrm{Ar}+\mathrm{N}_{2}$ plasma discharge, the gases being introduced into the chamber through separate mass flow controllers. Gas flows of 18 and $0.6 \mathrm{sccm}$ were used for Ar and $\mathrm{N}_{2}$, respectively, corresponding to a working pressure of $0.3 \mathrm{~Pa}$. The substrate was stationary during deposition and held at floating potential $(\sim-9 \mathrm{~V})$. To minimize the effect of layer thickness on column development, the deposition time was adjusted between 48 and $67 \mathrm{~min}$, so as to obtain HfN films with similar thicknesses $(\sim 1 \mu \mathrm{m})$ at different $\alpha$ angles.

\subsection{Characterization Methods}

The morphology of the as-deposited HfN coatings was observed by scanning electron microscopy (SEM) using a field emission gun JEOL 7001F-TTLS microscope (JEOL Ltd., Tokyo, Japan) operating at $30 \mathrm{kV}$. The cross-section images, the thickness and the column tilt angle $\beta$ of the OAD HfN films were determined. The deposition rate was calculated from the thickness and deposition time.

The crystal structure and phase identification of the OAD HfN films were studied by X-ray diffraction (XRD) using a Seifert Space XRD TS-4 diffractometer (GE Inspection Technologies GmbH, Ahrensburg, Germany) operating in Bragg-Brentano $\theta / 2 \theta$ configuration at $30 \mathrm{kV}$ and $30 \mathrm{~mA}$ using a 
$\mathrm{Cu} \mathrm{K} \alpha$ wavelength (1.5418 $\AA$ ). XRD patterns were measured along an angular $2 \theta$ range, from $30^{\circ}$ to $62^{\circ}$. This range covers the main diffraction lines of HfN, namely (111), (200), and (220), while avoiding the intense (004) Bragg reflection from the single-crystal Si substrate at $2 \theta=69.13^{\circ}$. XRD pole figures and XRD stress analysis were also performed using this diffractometer.

Pole figure measurements were carried out for $\{111\},\{200\}$, and $\{220\}$ reflections at several sets of $(\psi, \varphi)$ angles to determine the texture of the HfN films, where $\psi$ is the angle between the sample surface normal and the normal to a given (hkl) plane, and $\varphi$ is the azimuthal (polar) angle. Residual stress analysis of the examined samples was performed by means of the $\sin ^{2} \psi$ method using multiple $h k l$ reflections, known as the crystallite group method (CGM) [30,31]. The basic formalism of residual stress analysis, as well as details on the experimental procedure, can be found in References [31,32]. Because the HfN films deposited at $\alpha>25^{\circ}$ had a biaxial texture state, measurements of elastic strains by using the CGM have been carried out at specific $(\psi, \varphi)$ angles corresponding to intensity maxima of the following $\{111\},\{200\},\{220\}$, and $\{331\}$ diffracting plane families. These $(\psi, \varphi)$ angles vary from one sample to another due to different tilts of the [111] texture (see Section 3).

The electrical properties of the OAD HfN films were evaluated using van der Pauw's four-point probe method [33]. The average value of electrical resistivity was calculated from five measurements performed along two orthogonal in-plane directions of the coating (longitudinal and perpendicular to the projected incoming particle flux direction).

In parallel, computer simulations were carried out using the SIMTRA code [34] to simulate the transport of particles from the Hf target to the substrate. Prior to these calculations, the SRIM code [35] was used to calculate the energy and angular direction of the nascent particle flux (Hf sputtered atoms) leaving the target. A displacement energy threshold of $61 \mathrm{eV}$ was chosen for Hf [36] and the SRIM output file was used as the input parameter in the SIMTRA code. These simulations give us access to a set of useful information, such as angular distribution, number of particles arriving at the surface of the substrate, as well as average energy of particles arriving at the surface of the substrate.

\section{Results}

\subsection{Growth Morphology}

The growth morphology of OAD HfN films is shown in Figure 1. Films deposited at substrate inclination angle $\alpha \geq 35^{\circ}$ exhibit a columnar morphology, with columns extending throughout the entire film thickness. The columns are tilted towards the direction of the incoming flux. With increasing $\alpha$, the column tilt angle $\beta$ with respect to the substrate normal increases from $\beta=13^{\circ}$ (at $\alpha=35^{\circ}$ ) to $\beta=34^{\circ}$ (at $\alpha=85^{\circ}$ ). The columns are straight and have a relatively constant diameter $(\sim 100 \mathrm{~nm})$, except in the vicinity of the substrate interface where the column density is higher. The boundaries between columns are more distinctive with increasing $\alpha$, this clearly shows that porosity increases with increasing substrate inclination angle. However, at low substrate tilt angles $\alpha \leq 25^{\circ}$, it is not possible to distinguish any columnar features across the fracture SEM micrographs, the HfN layers are very dense, and show sign of repeated nucleation along the film thickness.

The substrate inclination angle $\alpha$ and deposition conditions completely change the morphology and microstructure of thin films. For HfN thin films, from the point of view of electrical properties, the change in microstructure is accompanied by variations in room temperature (RT) resistivity $(\rho)$ over several orders of magnitude (see Table 1). Increasing film porosity at higher substrate inclination angles $\alpha$ could be the main contribution to the loss of electrical conductivity in OAD HfN films due electron scattering at the column boundary [37]. At $\alpha=5^{\circ}, \rho=81 \mu \Omega \cdot \mathrm{cm}$, a value which is consistent with that of $70 \mu \Omega \cdot \mathrm{cm}$ reported for polycrystalline HfN films on glass at $300{ }^{\circ} \mathrm{C}$ [38] or epitaxial HfN films on $\mathrm{MgO}(001)$ obtained by pulsed-laser deposition $(44-75 \mu \Omega \cdot \mathrm{cm})$ [28] or by high-power impulse magnetron sputtering $(70 \mu \Omega \cdot \mathrm{cm})$ [39]. Note that the resistivity of stoichiometric epitaxial $\mathrm{HfN} / \mathrm{MgO}(001)$ layer grown at $650^{\circ} \mathrm{C}$ is $14.2 \mu \Omega \cdot \mathrm{cm}$ [40]. 

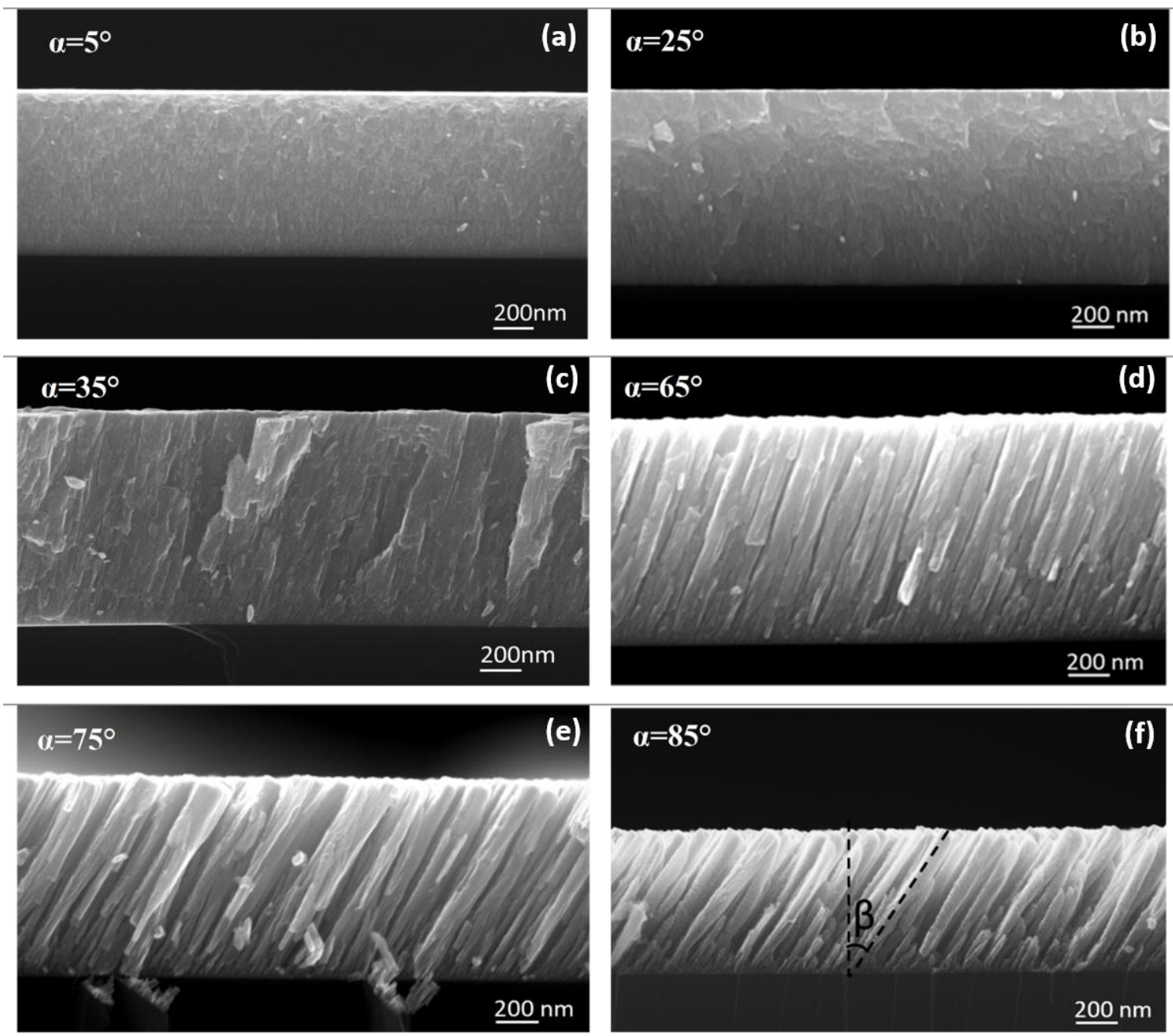

Figure 1. Cross-section SEM images of HfN films deposited at different substrate inclination angles: (a) $\alpha=5^{\circ}$, (b) $\alpha=25^{\circ}$, (c) $\alpha=35^{\circ}$, (d) $\alpha=65^{\circ}$, (e) $\alpha=75^{\circ}$, and (f) $\alpha=85^{\circ}$. The column tilt angle $\beta$ is indicated in (f).

Table 1. Influence of the substrate inclination angle $\alpha$ on the electrical resistivity and on the average energy of Hf sputtered particles and the number of collisions during transport in the gas phase at $0.3 \mathrm{~Pa}$ computed by SIMTRA code.

\begin{tabular}{ccccccc}
\hline Substrate Angle $\alpha\left(^{\circ}\right)$ & $\mathbf{5}$ & $\mathbf{2 5}$ & $\mathbf{3 5}$ & $\mathbf{6 5}$ & $\mathbf{7 5}$ & $\mathbf{8 5}$ \\
\hline Average Energy E $(\mathrm{eV})$ & 22.4 & 22.4 & 22.3 & 21.7 & 20.8 & 17.7 \\
\hline Number of Collisions & 7 & 7 & 8 & 10 & 12 & 20 \\
\hline RT Resistivity $\rho(\mu \Omega . c m)$ & $8.1 \times 10^{1}$ & $1.2 \times 10^{2}$ & $1.8 \times 10^{2}$ & $1.1 \times 10^{3}$ & $3.6 \times 10^{3}$ & $1.3 \times 10^{4}$ \\
\hline
\end{tabular}

\subsection{XRD Structural Investigations}

Figure 2 presents the XRD patterns of HfN films deposited at different inclination angles $\alpha$ of the substrate. Three main XRD lines, identified as (111), (200), and (220) peaks of Na-Cl-type cubic $\delta$ -HfN, are observed for all samples in the investigated $2 \theta$ range. It can be noticed that the intensity of these XRD lines changes noticeably with $\alpha$ : A stronger $\mathrm{I}_{111} /\left(\mathrm{I}_{111}+\mathrm{I}_{200}+\mathrm{I}_{220}\right)$ ratio is found for $\alpha>35^{\circ}$. In particular, a non-monotonic intensity variation of the (111) XRD line is found with increasing $\alpha$, as illustrated in Figure $2 b$. The intensity is maximum for the HfN film deposited at $\alpha=75^{\circ}$. This change in intensity is accompanied by a reduction of the (111) XRD line broadening from $\Gamma_{2 \theta}=0.77^{\circ}$ (at 
$\alpha=5^{\circ}$ ) to $\Gamma_{2 \theta}=0.37-0.40^{\circ}$ (at $\alpha=75$ and $85^{\circ}$ ), where $\Gamma_{2 \theta}$ is the full-width at half maximum of the (111) reflection.
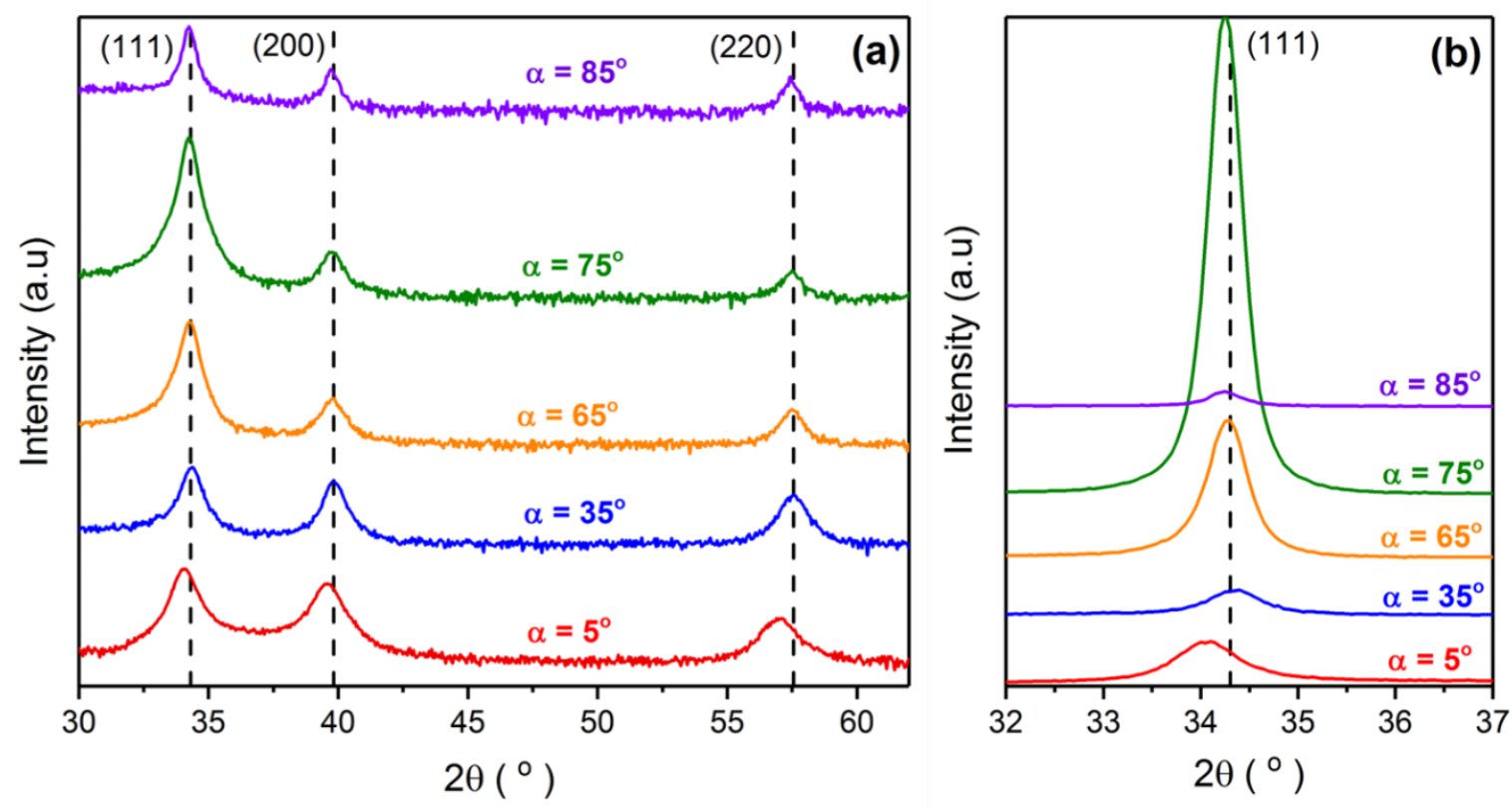

Figure 2. XRD patterns of OAD HfN films at different substrate inclination angles $\alpha$ : (a) logarithmic scale over $30^{\circ}-62^{\circ} 2 \theta$ range and $(\mathbf{b})$ intensity profile around the (111) peak in linear scale. For better clarity scans were shifted in vertical scale.

Further examination of the XRD patterns also reveals that the position of the different XRD lines coincides with the values of bulk HfN powder [41], except for the films deposited at $\alpha=5^{\circ}$ and $\alpha=25^{\circ}$ (not shown in Figure 2). For these films, a shift towards lower $2 \theta$ angles is found.

In order to understand the observed XRD intensity variations with $\alpha, \mathrm{XRD}$ pole figure measurements have been performed. Figure 3 shows the $\{111\}$ and $\{200\}$ pole figures for the HfN films with $\alpha=5^{\circ}, 35^{\circ}, 75^{\circ}$, and $85^{\circ}$. For $\alpha=5^{\circ}$, the pole figures are characteristic of a polycrystalline material with marginal out-plane preferred orientation. Overall, the intensity is rather homogenously distributed in the plane (along the $\varphi$ direction). A slight intensity reinforcement is observed along the flux direction $\left(\varphi=0^{\circ}\right)$ at $\psi \sim 8^{\circ}$ and $20^{\circ}$ for the (111) and (200) reflections, respectively. Similar findings were observed for the film deposited at $\alpha=25^{\circ}$. These results indicate that at low substrate inclination angles, the HfN films develop a polycrystalline growth with fiber-texture type.

The situation changes drastically for $\alpha \geq 35^{\circ}$, for which the XRD pole figures unveil the characteristics of a biaxial texture, i.e., the HfN films develop both out-of-plane and in-plane preferred orientations. For $\alpha=75^{\circ}$, the $\{111\}$ pole figure reveals a strong (111) texture, with one sharp maximum located at the center $\left(\psi=0^{\circ}\right.$ ) and three maxima located at $\psi=71^{\circ}$ for $\varphi=60,180$, and $300^{\circ}$ (see Figure 3e). Three intensity poles are found for the $\{200\}$ reflections, located at $\psi=54.7^{\circ}$, for $\varphi=0^{\circ}$, $120^{\circ}$ and $240^{\circ}$. The highest $\{200\}$ intensity is found along the incoming flux direction $\left(\varphi=0^{\circ}\right)$, see Figure 3f. Both pole figures evidence a threefold symmetry consistent with a (111)-oriented cubic crystal. The experimental data are in remarkable agreement with theoretical values, see intensity poles calculated using the CaRIne Crystallography software and represented as pink circles in Figure 3. 

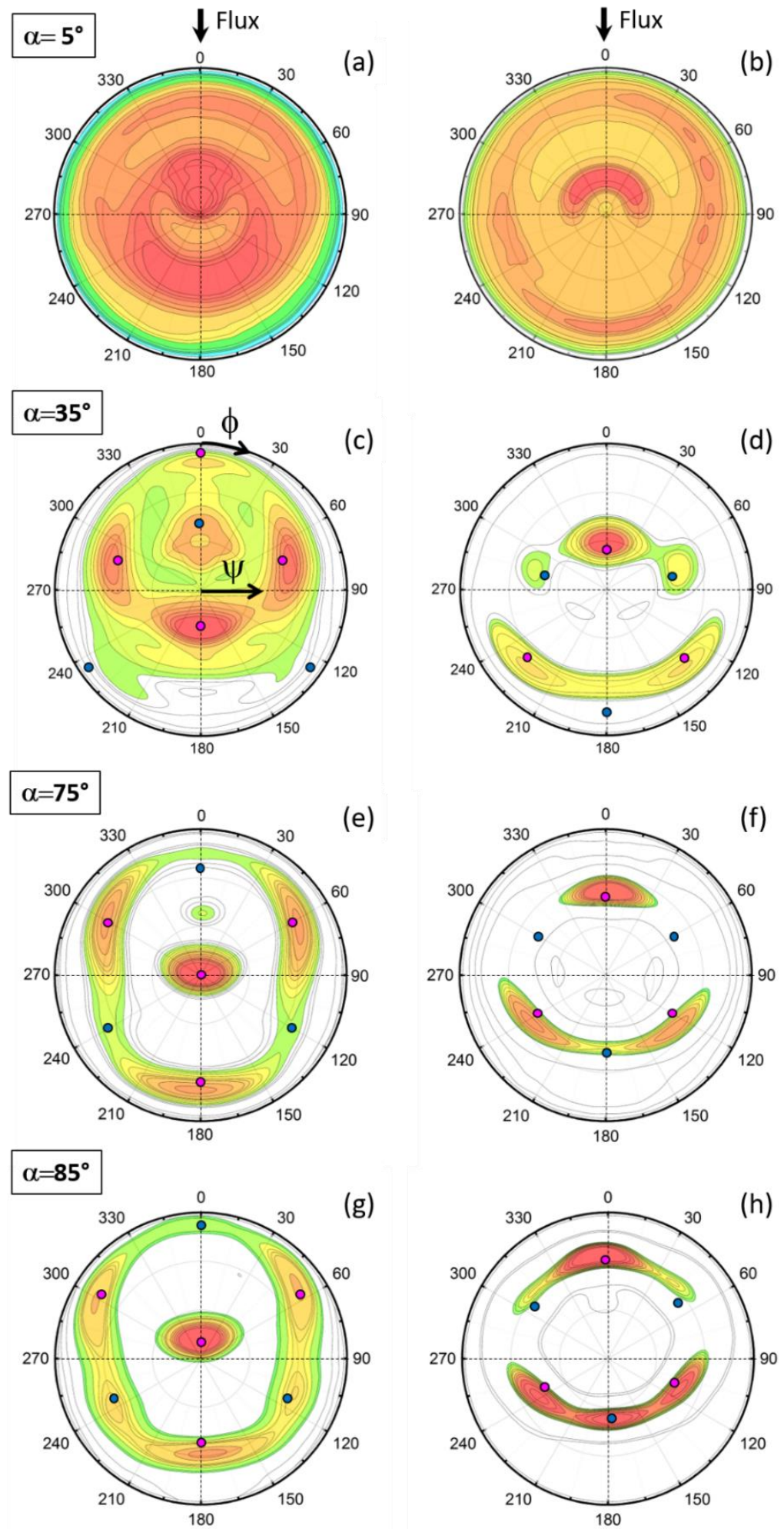

\{111\}

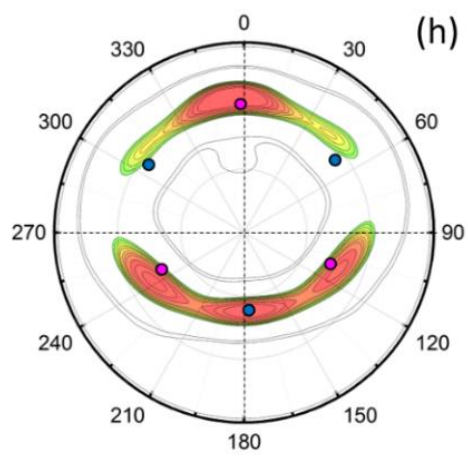

$\{200\}$

Figure 3. $\{111\}(\mathbf{a}, \mathbf{c}, \mathbf{e}, \mathbf{g})$ and $\{200\}(\mathbf{b}, \mathbf{d}, \mathbf{f}, \mathbf{h})$ X-ray diffraction (XRD) pole figures of oblique angle deposition (OAD) HfN films at different substrate inclination angles: $\alpha=5^{\circ}(\mathbf{a}, \mathbf{b}) ; \alpha=35^{\circ}(\mathbf{c}, \mathbf{d}) ; \alpha=75^{\circ}$ $(\mathbf{e}, \mathbf{f})$; and $\alpha=85^{\circ}(\mathbf{g}, \mathbf{h})$. The color scale corresponds to normalized iso-line intensity (in logarithmic scale). The theoretical intensity poles are displayed as filled circles: the blue symbols correspond to a $180^{\circ}$ in-plane rotation of the main growth variant shown in pink. The incoming flux direction is aligned along $\varphi=0^{\circ}$. 
The films deposited at $\alpha=35^{\circ}, 65^{\circ}$ and $85^{\circ}$ also exhibit a (111) biaxial texture, but the (111) planes are found to be tilted with respect to the sample surface, from $\zeta=-24.8^{\circ}$ to $+11.3^{\circ}$ with increasing $\alpha$, see $\{111\}$ pole figures of Figure 3 , as well as $\{111\}$ intensity profile taken along the $\psi$ direction at $\varphi=0^{\circ}$ displayed in Figure 4. For $\alpha=35^{\circ}$, the $\{111\}$ intensity poles are found at the following specific $(\psi, \varphi)$ values: $\left(88^{\circ} ; 0^{\circ}\right),\left(55^{\circ} ; 75^{\circ}\right),\left(25^{\circ} ; 180^{\circ}\right)$, and $\left(55^{\circ} ; 285^{\circ}\right)$. These values are in good agreement with calculated values assuming a [111] out-of-plane direction tilted by $-25^{\circ}$ with respect to the surface normal. However, additional intensity maxima are found at $\left(42^{\circ}, 0^{\circ}\right)$ and at $\left(47^{\circ}, 75^{\circ}\right) ;\left(47^{\circ}, 285^{\circ}\right)$ for the $\{111\}$ and $\{200\}$ pole figures, respectively, of the $\alpha=35^{\circ}$ sample (see Figure $3 c, d$ ). The presence of these additional, lower-intensity poles is well reproduced when considering a second growth variant, in-plane rotated by $\varphi=180^{\circ}$ (i.e., with respect to the [111] out-plane direction), see calculated blue circles. A similar situation is found for the HfN film deposited at $\alpha=85^{\circ}$, where the additional intensity poles are more clearly visible, see Figure $3 g, h$.

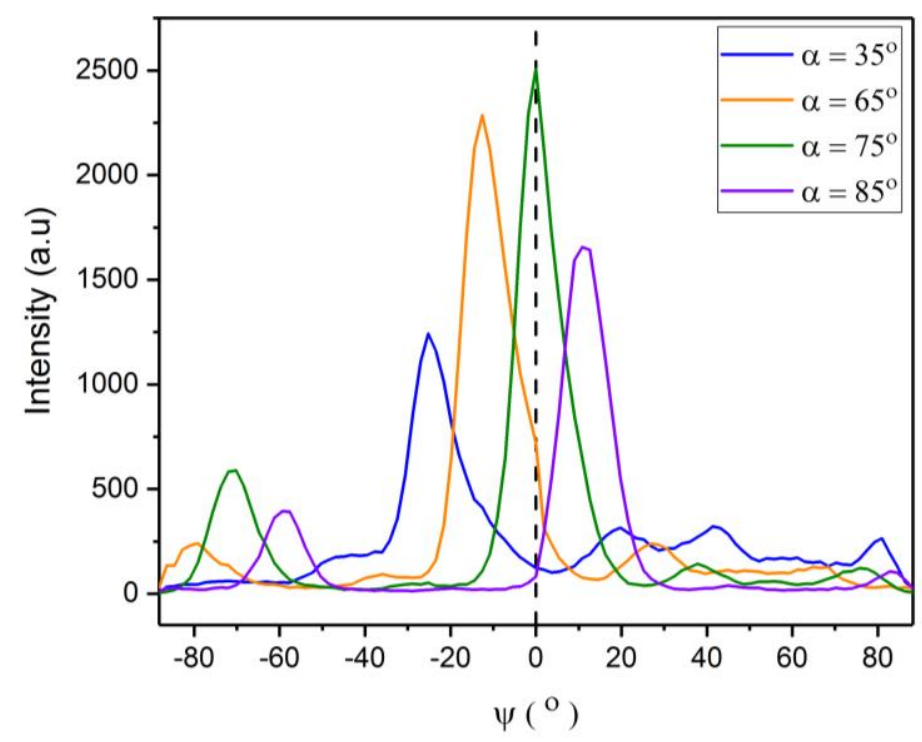

Figure 4. $\{111\}$ XRD intensity profile along the $\psi$ axis $\left(\right.$ at $\varphi=0^{\circ}$ ) for OAD HfN films at different substrate inclination angles $\alpha$.

It becomes obvious from the XRD data plotted in Figure 4 that the change in (111) XRD line intensity observed in $\theta-2 \theta$ scan (Figure $2 b$ ) is due to different tilts of the (111) crystallographic planes with respect to the sample surface. The tilt $\zeta$ varies from $-24.8^{\circ}\left(\alpha=35^{\circ}\right)$ to $-12.5^{\circ}\left(\alpha=65^{\circ}\right), \sim 0^{\circ}$ $\left(\alpha=75^{\circ}\right)$ and up to $+11.3^{\circ}\left(\alpha=85^{\circ}\right)$ (see Figure 4$)$. Therefore, measuring only $\theta-2 \theta$ scans for OAD or GLAD films can lead to erroneous interpretation of the preferred orientation.

Figure 5 summarizes the evolution of the column tilt angle $\beta$, together with the tilt angle $\zeta$ and $\eta$ of the (111) and (200) crystallographic planes with respect to the film surface, respectively, as a function of substrate inclination angle $\alpha$. Note that for $\alpha<35^{\circ}$, no $\beta$ values are reported due to the absence of columnar growth. A correlation between $\beta, \zeta$, and $\eta$ is uncovered from the present study, pointing out that the (microscopic) tilt angle of HfN nanocolumns and texture development share the same crystallographic origins. These results will be discussed in Section 4.2. 


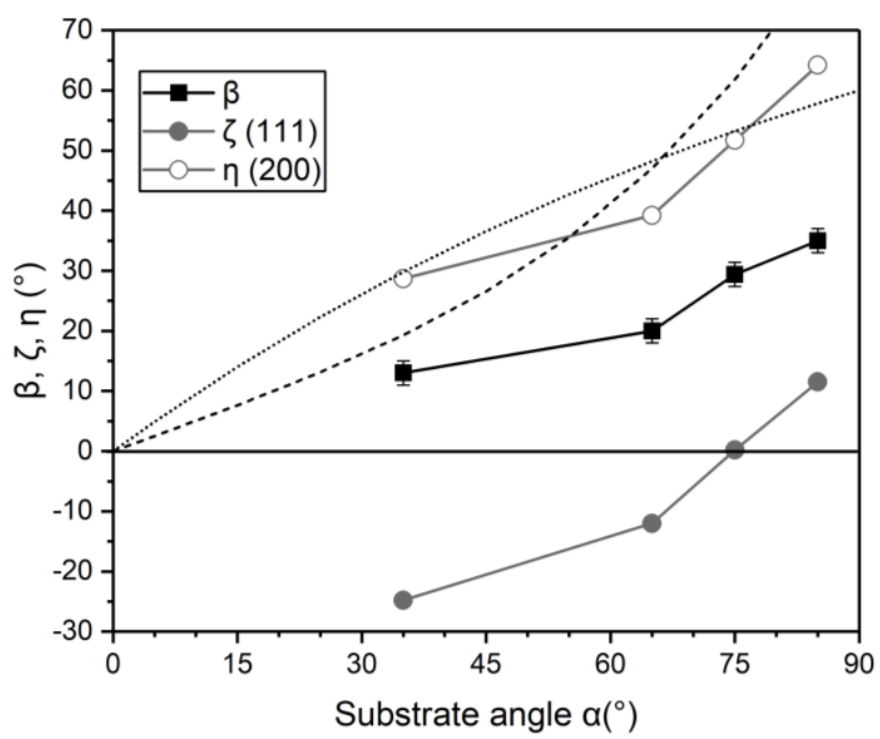

Figure 5. $\beta$ (column tilt angle), $\zeta$ and $\eta$ (crystal tilt angle) versus substrate inclination angle $\alpha$. The dashed (resp. dotted) line corresponds to the tangent (resp. cosine) empirical law.

\subsection{XRD Stress Analysis}

Representative examples of the evolution of the lattice parameter, $a$, of HfN films vs. $\sin ^{2} \psi$, as derived from XRD strain analysis, are displayed in Figure 6. Considering error bars, the measured $a$ values show a linear dependence with $\sin ^{2} \psi$. When comparing the data, one can clearly observe a reduction in the slope of the $\sin ^{2} \psi$ lines at higher $\alpha$ angles. Since the slope is proportional to the in-plane stress state, it can be concluded that the residual stress of $\mathrm{HfN}$ films deposited at oblique angles is significantly reduced compared to the HfN film deposited at normal incidence $\left(\alpha=5^{\circ}\right)$. For this latter sample, the slope is clearly negative, indicative of a compressive stress state. The quantitative analysis of these data will be presented and discussed in Section 4.3. For films deposited at high substrate inclination angles $\left(\alpha \geq 65^{\circ}\right)$, it can be noticed that the lattice parameter measured from the $\{200\}$ crystallographic planes does not follow the general trend (see the data point measured at $\psi=51.5^{\circ}$ in Figure $6 \mathrm{c}$ ), but is rather located close to the stress-free lattice parameter value ( $a_{\text {bulk }}=4.525 \AA$ [41]).
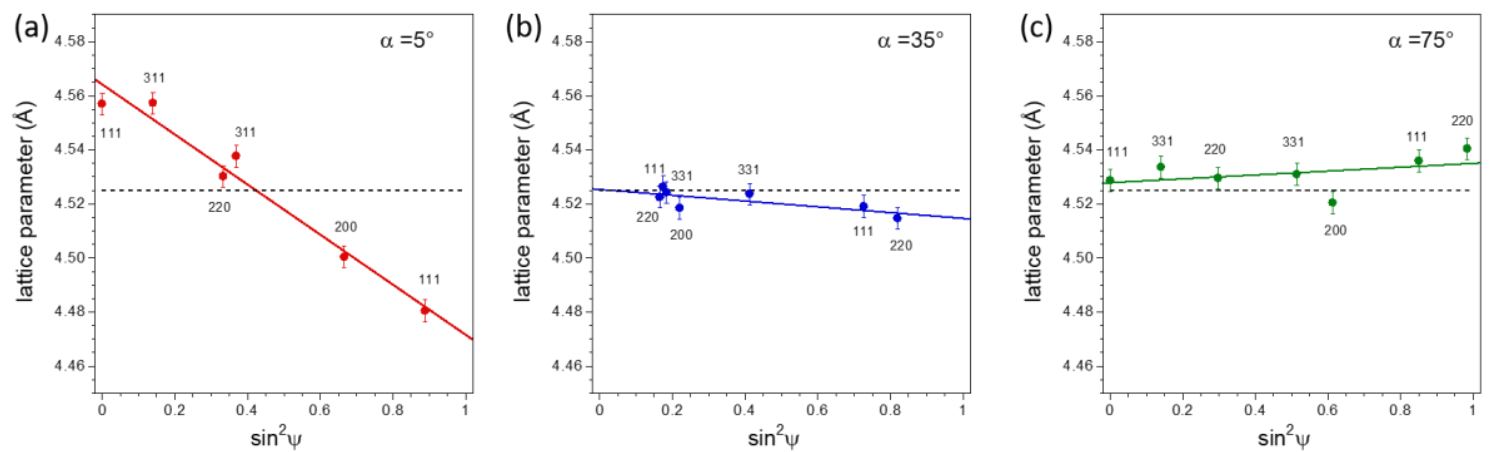

Figure 6. $\sin ^{2} \psi$ plots of the HfN films deposited at $\alpha=5^{\circ}(\mathbf{a}), \alpha=35^{\circ}(\mathbf{b})$, and $\alpha=75^{\circ}(\mathbf{c})$. The horizontal dashed line corresponds to the bulk lattice parameter of HfN reference powder $\left(a_{\text {bulk }}=4.525 \AA\right)$. The measured $h k l$ reflections are indicated in each graph.

\section{Discussion}

\subsection{Tilted Columnar Growth}

Cross-sectional SEM imaging of the fractured surfaces clearly attests of the formation of tilted columnar morphology for the HfN films deposited at $\alpha \geq 35^{\circ}$ (see Figure 1). The columns are tilted 
towards the incoming flux direction. This is typical for thin films deposited off-normally (such as GLAD or OAD) under conditions of low-atomic mobility, where the growth is governed by shadowing effects $[2,6]$. At low $\alpha$ angle, no columnar structure develops for HfN films due to secondary nucleation induced by the impingement of energetic particles (sputtered Hf and backscattered Ar) reaching the substrate. The average energy of sputtered Hf particles, as calculated from SIMTRA, are reported in Table 1. With increasing $\alpha$ angle, the energy of the sputtered atoms decreases from 22.4 to $17.7 \mathrm{eV}$. Besides the contribution of deposited energy, the development of a dense morphology at low incidence angle $\left(5^{\circ}\right.$ and $\left.25^{\circ}\right)$ is imputable to the absence of shadowing effect below a critical angle. The value of this critical angle depends on material type and deposition conditions $[7,10]$.

The inclination angle of columns increases gradually from $13^{\circ}$ to $34^{\circ}$ with increasing $\alpha$ from $35^{\circ}$ to $85^{\circ}$. This range is similar to what we reported previously for sputter-deposited TiN films using the same configurational setup [21], with $\beta$ values ranging from $\sim 5^{\circ}$ to $25^{\circ}$ at the same working pressure of $0.3 \mathrm{~Pa}$. These values are much lower than what is usually reported for GLAD films obtained using thermal evaporation. This is related to the collisional transport processes specific to plasma-based PVD as compared to line-of-sight trajectories for thermal evaporation. Sputtered particles will experience collisions (and change in trajectory direction) with the Ar gas atoms during their transport from the target to the substrate, leading to a spreading of the angular distribution of particles arriving at the substrate. This is illustrated in Figure 7 for HfN films deposited at $0.3 \mathrm{~Pa}$. For example, at $\alpha=35^{\circ}$, the FWHM of the distribution is $\sim 20^{\circ}$.With increasing $\alpha$, the number of particles reaching the substrate decreases but there exists also a higher fraction of particles, initially out of sight from the substrate, that can be collected as result of increasing number of collisions with $\alpha$ (see Table 1). Overall, these angular distributions are centered to the geometrically set $\alpha$ values (see Figure 7). At $\alpha=5^{\circ}$, the influence of target racetrack is visible and shifts the maximum of the distribution to $10^{\circ}$, while at $\alpha=85^{\circ}$, a non-negligible skew towards lower angles is observed. In the absence of surface diffusion, kinetic Monte Carlo simulations of the growth morphology of OAD TiN films have shown that the column tilt angle $\beta$ is dictated by the angular distribution of the incoming particle flux [21]. Besides this effect, other mechanisms related to hyperthermal particles, such as re-sputtering or dragging mechanism [7], can contribute to straighten the columns in sputtered OAD films, by reducing the atomic shadowing effect [42].

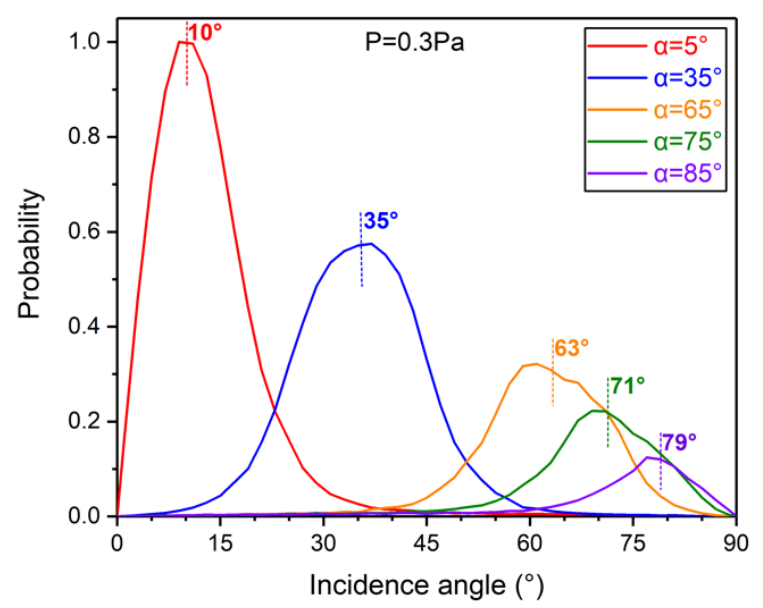

Figure 7. Angular distribution of sputtered Hf particles at the substrate position calculated using SIMTRA code for various inclination angles $\alpha$ of the substrate, at fixed Ar working pressure (0.3 Pa). The number of particles was normalized to the maximum value obtained at $\alpha=5^{\circ}$.

As can be seen from Figure 5, the $\beta$ values for sputtered HfN films are much lower than those predicted by either the empirical tangent law $\left(\tan \beta=\frac{1}{2} \tan \alpha\right)[43]$ or $\operatorname{cosine~law~}(\beta=\alpha-\arcsin [(1-\cos$ $\alpha) / 2]$ ) derived by Tait et al. from a simulation program based on 2D hard discs [44]. Although these two laws are often used for comparison to experimental data, there exists a number of reports that show 
that these two equations are not universal, as $\beta$ is dependent on the material type [45] and deposition conditions [7,46]. For instance, the surface trapping mechanism proposed by Alvarez et al. [46] mediates the shadowing effect by considering short-range interaction of the incoming particles with the film surface, resulting in lower $\beta$ angles with increasing surface trapping probability $\left(\mathrm{s}_{\mathrm{t}}\right)$. Since the values of $s_{t}$ of both Hf and $\mathrm{N}$ species on HfN surface are not available, it is difficult to quantify this contribution in the present study. However, due to the metallic character of HfN, one would expect a relatively low value of $\mathrm{s}_{t}$ [46]. Also, we can neglect the contribution of thermally-induced surface diffusion processes due to deposition at low homologous temperature, $T_{h} \leq 0.16$. Therefore, we suggest the observed variation of $\beta$ versus $\alpha$ for OAD HfN films to be primarily governed by the angular and energy distribution of the vapor flux.

\subsection{Development of In-Plane and Out-of-Plane Crystallographic Orientations}

The HfN films deposited at oblique angles $\left(\alpha \geq 35^{\circ}\right)$ exhibit a preferred [111] out-plane orientation. The analysis of XRD pole figures displayed in Figure 3 has disclosed that the [111] axis is tilted with respect to the surface normal, except at $\alpha=75^{\circ}$, for which the (111) pole coincides with the center of the pole figure. The [111] out-of-plane orientation tilt angle $\zeta$ gradually increases from $-24.8^{\circ}$ to $11.3^{\circ}$ with increasing $\alpha$ angle, i.e., the texture axis also tilts towards the vapor flux direction. Besides, its evolution is correlated to the variation of the column tilt angle $\beta$, (see Figure 5), indicating that the geometrical tilt of the column (sub-micron scale) is governed by the tilting of crystallographic planes, i.e., by atomistic processes, as discussed hereafter. It has to be pointed out that off-axis texture has been found for other TMN films, for instance in OAD TiAlN films sputter-deposited at $\alpha=45$ and $60^{\circ}$ [47].

Based on the evolutionary growth model proposed by van der Drift [48], the grains with the geometrically fastest growing direction perpendicular to the substrate will overgrow all other grains, and continue to grow upon further material capture, resulting into the development of a preferred out-of-plane orientation. In the case of TMN with rocksalt structure, the fastest growing direction has been shown to depend on the chemical state of the adparticles and reactive gas [26]. Under conditions of atomic nitrogen supply, which is the case at low $\mathrm{p}_{\mathrm{N} 2}$ used in the present work, the fastest geometric growth direction is [111], corresponding to $\{100\}$ crystal facets. Indeed, the $\{100\}$ planes have the lowest surface energy (i.e., highest diffusivity) and are therefore the planes offering the lowest crystallographic growth rate [26]. This description is consistent with the present findings for HfN films. The poles of the $\{200\}$ pole figure correspond to the $\{100\}$ facets, i.e., crystal habits. The threefold symmetry observed in Figure 3 indicates that the growing crystals have a pyramidal shape, with (111) triangular base plane. Plan-view SEM (see Figure 8b) confirms the emergence of pyramids at the surface of HfN films for $\alpha \geq 65^{\circ}$. Similar results were reported for TiN films deposited at $\alpha=65^{\circ}$ [26].

(a)

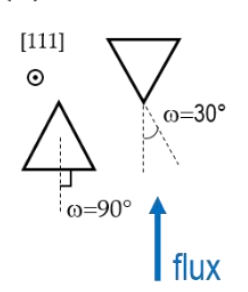

(b)

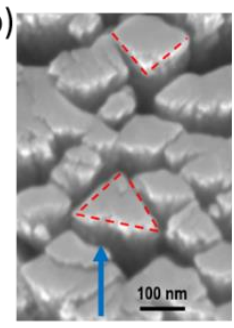

(c)

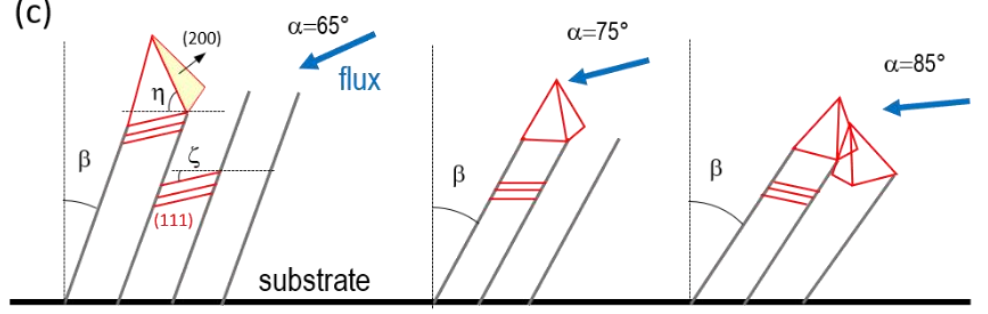

Figure 8. (a) Schematic representation of in-plane orientation of $2 \mathrm{D}$ triangular-shaped crystals with [111] out-of-plane orientation and $\{100\}$ facets, (b) plan-view SEM image of the $\alpha=75^{\circ} \mathrm{HfN}$ film showing two different orientations of the crystal facets with respect to incoming flux and (c) Schematics of HfN columnar development ( $\beta$ angle) and texture tilt angle $\zeta$ with increasing $\alpha$ angle. The (blue) arrow indicates the vapor flux direction.

The XRD pole figure results have also revealed that the HfN films have a biaxial texture, with a preferential alignment along two specific in-plane directions, for $\alpha \geq 35^{\circ}$. The more intense (200) pole was located along the $\varphi=0^{\circ}$ direction, i.e., along the projected flux direction, while a less intense 
set of poles was observed, $180^{\circ}$ apart (also equivalent to a $60^{\circ}$ rotation). It can be concluded that the vast majority of pyramidal-shaped crystals have their $\{100\}$ facets facing the incoming flux, but some other crystals are aligned with their corner along the projected flux direction. The origin of this double in-plane alignment can be explained by the analytical model proposed by Mahieu et al. [26]. This model is based on the calculation of the 2D capture cross-section of individual crystals. The orientation that maximizes the capture length should capture more adatoms and overgrow all other non-favored crystal orientations. For a [111] out-of-plane orientation with $\{100\}$ crystal habits, the capture length has two equivalent maxima for in-plane orientations of $\omega=30^{\circ}$ and $\omega=90^{\circ}$, corresponding to a triangular-shaped crystal with a top $\left(30^{\circ}\right)$ or a side $\left(90^{\circ}\right)$ towards the incoming flux, see Figure 8 a. This is confirmed by SEM imaging, see Figure $8 \mathrm{~b}$. While for TiN films, a single in-plane alignment was observed (corresponding to $90^{\circ}$ case), the present findings of a double in-plane alignment for HfN films deposited at $\alpha \geq 35^{\circ}$ provide experimental support to the 2D model proposed by Mahieu et al. [26]. Examples of double in-plane alignments in off-normally sputter-deposited metal and oxide films have been reported by Elofsson et al. for Cr films [49] and Saraiva and Depla [14] for $\mathrm{Mg}-\mathrm{M}-\mathrm{O}(\mathrm{M}=\mathrm{Al}, \mathrm{Cr}$, and Ti) films.

If the in-plane orientation of the crystals can be explained by 2D calculations of the capture length, and reflects some azimuthal constraint of the crystallites along the projected flux direction at GLAD conditions, the origin of the texture tilt angle requires some 3D modelling. A simple rationale consists in assuming that the growing cubic crystal will align in such a way that its $\{100\}$ facets are perpendicular to the incident vapor flux. Considering the observed $\eta$ values (Figure 5) and angular distribution (Figure 7) makes such scenario plausible. A schematic of the columnar growth of HfN films is displayed in Figure $8 c$, showing the qualitative evolution of $\zeta \eta$ and $\beta$ angles with $\alpha$ angle.

\subsection{Stress Evolution}

The stress state in the OAD HfN films was determined from the analysis of the elastic strain probed by XRD using the $\sin ^{2} \psi$ method. The $\sin ^{2} \psi$ plots show linear dependence of the lattice spacing with $\sin ^{2} \psi$ (see Figure 6). The existence of shear stress components in the stress tensor can be ruled out as no $\psi$-splitting could be noticed in measurements performed at positive and negative $\psi$ values. Also, there was no obvious dependence of the lattice spacing to the in-plane direction (i.e., at different $\varphi$ values), which suggests that the residual stress state in these layers is isotropic in the film plane, i.e., corresponds to an equi-biaxial stress state: $\sigma_{11}=\sigma_{22}=\sigma$. To derive the stress $\sigma$ from the XRD elastic strain data, the following single-crystal elastic constants were used for HfN: $\mathrm{c}_{11}=588 \mathrm{GPa}$, $c_{12}=113 \mathrm{GPa}$ and $\mathrm{c}_{44}=120 \mathrm{GPa}$, taken from ab-initio calculations (at $0 \mathrm{~K}$ ) by Holec et al. [50]. To get an idea on the error associated with the use of one or another set of elastic constants, the analysis was also performed by considering the mechanical elastic constants [30] of polycrystalline HfN material, which solely depend on the Young modulus $E=391 \mathrm{GPa}$ and Poisson ratio $v=0.26$ [51].

Figure 9 displays the evolution of $\sigma$ as a function of substrate inclination angle $\alpha$. It can be observed that the stress is largely compressive ( -6 to $-4 \mathrm{GPa}$ ) for the HfN films deposited at near normal incidence, $\alpha=5^{\circ}$, and at $\alpha=25^{\circ}$. It relaxes significantly for HfN films that exhibit a tilted columnar morphology and biaxial texture, i.e., for $\alpha \geq 35^{\circ}$, reaching an almost stress-free state at $\alpha=85^{\circ}$. The stress-free lattice parameter, $a_{0}$, of the HfN films was also derived from the XRD strain analysis: $a_{0}$ values range from 4.521 to $4.530 \AA$, in good agreement with reported values of 4.525 [41] and $4.532 \AA$ [51] for bulk HfN compounds, as well as $a_{0}$ value of $4.524 \AA$ for epitaxial stoichiometric HfN layer [40]. This suggests that the chemical composition of crystalline domains inside HfN columns is close to the Hf:N stoichiometric 1:1 ratio, with negligible impurities.

The origin of intrinsic stress in low-mobility material thin films deposited at normal incidence is well documented in the literature $[31,32,52,53]$. Typically, the intrinsic stress in columnar films is tensile under conditions of thermal evaporation due to attractive forces at the column boundary. When the growing layers are subjected to continuous bombardment by energetic particles, such as using plasma discharges in magnetron sputtering, the net stress is compressive and dominated by densification 
and defect incorporation into non-lattice sites (interstitial sites, grain boundaries) [54,55]. In situ and real-time studies of stress evolution in TiN, $\mathrm{ZrN}$, and TaN sputter-deposited films [56-58] have shown that tensile and compressive stress sources are competing during growth. In the case of TaN, the stress reaches a compressive steady-state of $\sim-5 \mathrm{GPa}$ [58]. The HfN film deposited at $\alpha=5^{\circ}$ shows similar stress values. The very dense microstructure observed in Figure $1 \mathrm{a}$ is consistent with intense particle bombardment arising from sputtered atoms (with average energy of $22.4 \mathrm{eV}$, see Table 1) as well as reflected Ar (average energy of $59.6 \mathrm{eV}$ ).

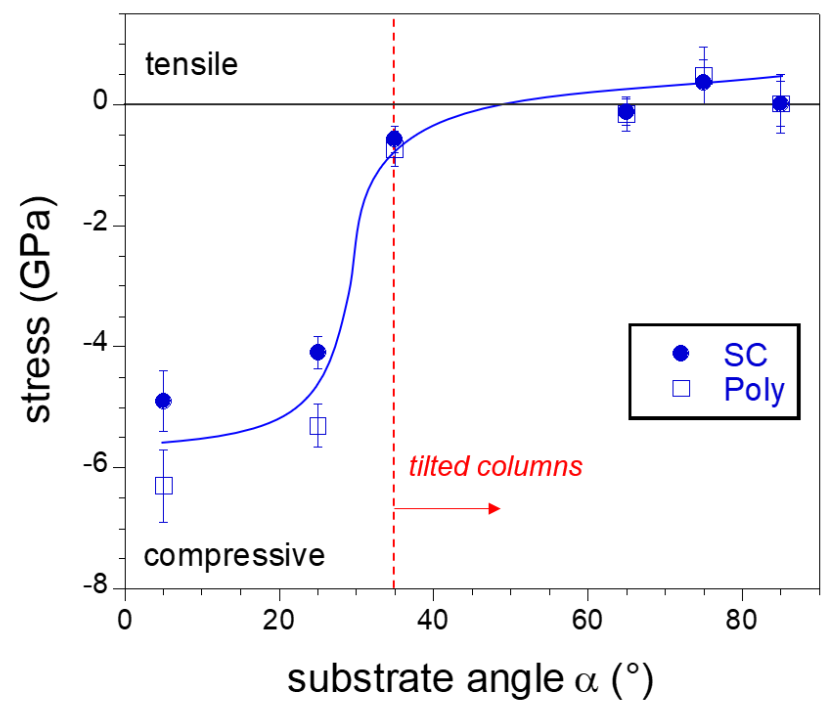

Figure 9. Biaxial stress in OAD HfN films vs. substrate inclination angle $\alpha$. The labels "SC" and "Poly" refer respectively to the single-crystal (SC) and mechanical (Poly) elastic constants used for the analysis. The blue solid line serves as guide for the eye.

However, studies on the stress evolution in thin films deposited at off-normal conditions remain scarce $[8,59,60]$. Siad et al. [8] have reported a critical angle of $\alpha \sim 60^{\circ}$ above which the absolute stress magnitude decreases for $\mathrm{Al}, \mathrm{Ti}$, and $\mathrm{Cr}$ films. They attributed this change to self-shadowing effect and decrease of average energy of incoming particles. In the present work, the decrease of compressive stress observed in HfN films with increasing inclination angle $\alpha$ is consistent with the development of more tilted columns and increase of voids fraction between columns, as a result of shadowing effect and lower deposited energy (see Table 1), as discussed already in Section 4.1. Using in situ wafer curvature measurements, Yu and Thompson [60] have evidenced a change from compressive to tensile stress with increasing $\alpha$ angle in evaporated $\mathrm{Ni}$ and $\mathrm{Au}$ films. They attributed these findings to a lower propensity for adatoms to be incorporated at the grain boundaries due to an increase in surface roughness. This mechanism can also contribute to the observed intrinsic stress transition observed for HfN films with increasing inclination angle of the substrate.

\section{Conclusions}

The present work has demonstrated that the resulting film morphology, texture and stress state in HfN films deposited at OAD conditions are strongly affected by the vapor flux direction. With increasing substrate inclination angles $\alpha$, the film microstructure evolves from a dense packing of nanosized grains and fiber-texture to well-defined columns tilted towards the flux direction, and development of a biaxial texture with double in-plane alignment.

Analysis of the XRD pole figures of HfN films deposited at $\alpha \geq 35^{\circ}$ reveal that the growing crystals consist of [111]-oriented pyramids terminated by $\{100\}$ facets, which orientate in such a way that the $\{100\}$ crystal habit is perpendicular to the incoming flux, or is in-plane tilted by $60^{\circ}$ (corresponding to a 
corner facing the flux). These two in-plane alignments correspond to the maximum capture length of adatoms predicted by 2D calculations.

We also report that the [111] texture axis does not correspond to the microscopic column tilt angle $\beta$, but both move concomitantly towards the flux direction with increasing $\alpha$. The development of slanted columns is accompanied by higher surface roughness and porosity, significant reduction of compressive stress and lower film conductivity.

Author Contributions: Conceptualization, G.A. and C.M.; methodology, F.A. and R.M.; software, R.M.; validation, G.A., R.M. and F.A.; formal analysis, R.M.; writing — original draft preparation, R.M., F.A. and G.A.; writing-review and editing, G.A., supervision, C.M. and G.A.; project administration, G.A.; funding acquisition, F.A., R.M. and G.A.

Funding: This work partially pertains to the French Government program "Investissements d'Avenir" (LABEX INTERACTIFS, reference ANR-11-LABX-0017-01).

Acknowledgments: The authors wish to acknowledge Philippe Guérin for his assistance and technical support on the deposition process. RM acknowledges the French Ministry for Europe and Foreign Affairs for financial support through the Eiffel Excellence Scholarship Program (contract 919884J). FA acknowledges the Scientific and Technical Research Council of Turkey (TUBITAK) for fellowship granted in the frame of 2219-International Post-Doctoral Research Fellowship (contract 1059B191800197).

Conflicts of Interest: The authors declare no conflict of interest.

\section{References}

1. Xi, J.Q.; Schubert, M.F.; Kim, J.K.; Schubert, E.F.; Chen, M.; Lin, S.Y.; Liu, W.; Smart, J.A. Optical thin-film materials with low refractive index for broadband elimination of Fresnel reflection. Nat. Photonics 2007, 1, 176-179. [CrossRef]

2. Robbie, K.; Brett, M.J. Sculptured thin films and glancing angle deposition: Growth mechanics and applications. J. Vac. Sci. Technol. A Vac. Surf. Films 1997, 15, 1460-1465. [CrossRef]

3. Hawkeye, M.M.; Brett, M.J. Glancing angle deposition: Fabrication, properties, and applications of microand nanostructured thin films. J. Vac. Sci. Technol. A Vac. Surf. Films 2007, 25, 1317-1335. [CrossRef]

4. Barranco, A.; Borras, A.; Gonzalez-Elipe, A.R.; Palmero, A. Perspectives on oblique angle deposition of thin films: From fundamentals to devices. Prog. Mater. Sci. 2016, 76, 59-153. [CrossRef]

5. Patzig, C.; Karabacak, T.; Fuhrmann, B.; Rauschenbach, B. Glancing angle sputter deposited nanostructures on rotating substrates: Experiments and simulations. J. Appl. Phys. 2008, 104, 094318. [CrossRef]

6. Mukherjee, S.; Gall, D. Structure zone model for extreme shadowing conditions. Thin Solid Films 2013, 527, 158-163. [CrossRef]

7. Alvarez, R.; Garcia-Martin, J.M.; Garcia-Valenzuela, A.; Macias-Montero, M.; Ferrer, F.J.; Santiso, J.; Rico, V.; Cotrino, J.; Gonzalez-Elipe, A.R.; Palmero, A. Nanostructured Ti thin films by magnetron sputtering at oblique angles. J. Phys. D Appl. Phys. 2016, 49, 045303. [CrossRef]

8. Siad, A.; Besnard, A.; Nouveau, C.; Jacquet, P. Critical angles in DC magnetron glad thin films. Vacuum 2016, 131, 305-311. [CrossRef]

9. Dervaux, J.; Cormier, P.A.; Moskovkin, P.; Douheret, O.; Konstantinidis, S.; Lazzaroni, R.; Lucas, S.; Snyders, R. Synthesis of nanostructured Ti thin films by combining glancing angle deposition and magnetron sputtering: A joint experimental and modeling study. Thin Solid Films 2017, 636, 644-657. [CrossRef]

10. Pedrosa, P.; Ferreira, A.; Cote, J.M.; Martin, N.; Yazdi, M.A.P.; Billard, A.; Lanceros-Mendez, S.; Vaz, F. Influence of the sputtering pressure on the morphological features and electrical resistivity anisotropy of nanostructured titanium films. Appl. Surf. Sci. 2017, 420, 681-690. [CrossRef]

11. Alvarez, R.; Garcia-Valenzuela, A.; Rico, V.; Garcia-Martin, J.M.; Cotrino, J.; Gonzalez-Elipe, A.R.; Palmero, A. Kinetic energy-induced growth regimes of nanocolumnar Ti thin films deposited by evaporation and magnetron sputtering. Nanotechnology 2019, 30, 475603. [CrossRef] [PubMed]

12. Zhou, C.M.; Li, H.F.; Gall, D. Multi-component nanostructure design by atomic shadowing. Thin Solid Films 2008, 517, 1214-1218. [CrossRef]

13. Lamas, J.S.; Leroy, W.P.; Lu, Y.G.; Verbeeck, J.; Van Tendeloo, G.; Depla, D. Using the macroscopic scale to predict the nano-scale behavior of YSZ thin films. Surf. Coat. Technol. 2014, 238, 45-50. [CrossRef]

14. Saraiva, M.; Depla, D. Texture and microstructure in co-sputtered $\mathrm{Mg}-\mathrm{M}-\mathrm{O}(\mathrm{M}=\mathrm{Mg}, \mathrm{Al}, \mathrm{Cr}, \mathrm{Ti}, \mathrm{Zr}$, and $\mathrm{Y})$ films. J. Appl. Phys. 2012, 111, 104903. [CrossRef] 
15. El Beainou, R.; Martin, N.; Potin, V.; Pedrosa, P.; Yazdi, M.A.P.; Billard, A. W-Cu sputtered thin films grown at oblique angles from two sources: Pressure and shielding effects. Surf. Coat. Technol. 2018, 343, 153-159. [CrossRef]

16. Mahieu, S.; Ghekiere, P.; De Winter, G.; De Gryse, R.; Depla, D.; Van Tendeloo, G.; Lebedev, O.I. Biaxially aligned titanium nitride thin films deposited by reactive unbalanced magnetron sputtering. Surf. Coat. Technol. 2006, 200, 2764-2768. [CrossRef]

17. Kumar, K.K.; Raole, P.M.; Rayjada, P.A.; Chauhan, N.L.; Mukherjee, S. Study of structure development of titanium nitride on inclined substrates. Surf. Coat. Technol. 2011, 205, S187-S191. [CrossRef]

18. Xie, Z.; Liu, X.; Wang, W.; Liu, C.; Li, Z.; Zhang, Z. Fabrication of TiN nanostructure as a hydrogen peroxide sensor by oblique angle deposition. Nanoscale Res. Lett. 2014, 9, 105. [CrossRef]

19. Qi, Z.; Wei, B.; Wang, J.; Yang, Y.; Wang, Z. Nanostructured porous CrN thin films by oblique angle magnetron sputtering for symmetric supercapacitors. J. Alloys Compd. 2019, 806, 953-959. [CrossRef]

20. Phae-ngam, W.; Horprathum, M.; Chananonnawathorn, C.; Lertvanithphol, T.; Samransuksamer, B.; Songsiriritthigul, P.; Nakajima, H.; Chaiyakun, S. Oblique angle deposition of nanocolumnar TiZrN films via reactive magnetron co-sputtering technique: The influence of the $\mathrm{Zr}$ target powers. Curr. Appl. Phys. 2019, 19, 894-901. [CrossRef]

21. Bouaouina, B.; Mastail, C.; Besnard, A.; Mareus, R.; Nita, F.; Michel, A.; Abadias, G. Nanocolumnar TiN thin film growth by oblique angle sputter-deposition: Experiments vs. simulations. Mater. Des. 2018, 160, 338-349. [CrossRef]

22. Patsalas, P.; Kalfagiannis, N.; Kassavetis, S.; Abadias, G.; Bellas, D.V.; Lekka, C.; Lidorikis, E. Conductive nitrides: Growth principles, optical and electronic properties, and their perspectives in photonics and plasmonics. Mater. Sci. Eng. R Rep. 2018, 123, 1-55. [CrossRef]

23. Lalisse, A.; Tessier, G.; Plain, J.; Baffou, G. Plasmonic efficiencies of nanoparticles made of metal nitrides (TiN, ZrN) compared with gold. Sci. Rep. 2016, 6, 38647. [CrossRef] [PubMed]

24. Popov, A.A.; Tselikov, G.; Dumas, N.; Berard, C.; Metwally, K.; Jones, N.; Al-Kattan, A.; Larrat, B.; Braguer, D.; Mensah, S.; et al. Laser- synthesized TiN nanoparticles as promising plasmonic alternative for biomedical applications. Sci. Rep. 2019, 9, 1-11. [CrossRef] [PubMed]

25. Hentschel, M.; Schäferling, M.; Duan, X.; Giessen, H.; Liu, N. Chiral plasmonics. Sci. Adv. 2017, 3, e1602735. [CrossRef]

26. Mahieu, S.; Ghekiere, P.; Depla, D.; De Gryse, R. Biaxial alignment in sputter deposited thin films. Thin Solid Films 2006, 515, 1229-1249. [CrossRef]

27. Laforge, J.M.; Ingram, G.L.; Taschuk, M.T.; Brett, M.J. Flux engineering to control in-plane crystal and morphological orientation. Cryst. Growth Des. 2012, 12, 3661-3667. [CrossRef]

28. Farrell, I.L.; Reeves, R.J.; Preston, A.R.H.; Ludbrook, B.M.; Downes, J.E.; Ruck, B.J.; Durbin, S.M. Tunable electrical and optical properties of hafnium nitride thin films. Appl. Phys. Lett. 2010, 96, 071914. [CrossRef]

29. Kumar, M.; Umezawa, N.; Ishii, S.; Nagao, T. Examining the Performance of Refractory Conductive Ceramics as Plasmonic Materials: A Theoretical Approach. ACS Photonics 2016, 3, 43-50. [CrossRef]

30. Noyan, I.C.; Cohen, J.B. Residual Stress Measurement by Diffraction and Interpretation; Springer: New York, NY, USA, 1987.

31. Abadias, G. Stress and preferred orientation in nitride-based PVD coatings. Surf. Coat. Technol. 2008, 202, 2223-2235. [CrossRef]

32. Abadias, G.; Chason, E.; Keckes, J.; Sebastiani, M.; Thompson, G.B.; Barthel, E.; Doll, G.L.; Murray, C.E.; Stoessel, C.H.; Martinu, L. Review Article: Stress in thin films and coatings: Current status, challenges, and prospects. J. Vac. Sci. Technol. A 2018, 36, 020801. [CrossRef]

33. Bierwagen, O.; Pomraenke, R.; Eilers, S.; Masselink, W.T. Mobility and carrier density in materials with anisotropic conductivity revealed by van der Pauw measurements. Phys. Rev. B 2004, 70, 165307. [CrossRef]

34. Van Aeken, K.; Mahieu, S.; Depla, D. The metal flux from a rotating cylindrical magnetron: A Monte Carlo simulation. J. Phys. D Appl. Phys. 2008, 41, 205307. [CrossRef]

35. Ziegler, J.F.; Biersack, J.P.; Littmark, U. The Stopping and Range of Ions in Matter; Pergamon Press: New York, NY, USA, 1985.

36. Konobeyev, A.Y.; Fischer, U.; Korovin, Y.A.; Simakov, S.P. Evaluation of effective threshold displacement energies and other data required for the calculation of advanced atomic displacement cross-sections. Nucl. Energy Technol. 2017, 3, 169-175. [CrossRef] 
37. Besnard, A.; Martin, N.; Carpentier, L.; Gallas, B. A theoretical model for the electrical properties of chromium thin films sputter deposited at oblique incidence. J. Phys. D Appl. Phys. 2011, 44, 215301. [CrossRef]

38. Shinkai, S.; Sasaki, K. Influence of sputtering parameters on the formation process of high-quality and low-resistivity HfN thin film. Jpn. J. Appl. Phys. 1999, 38, 2097-2102. [CrossRef]

39. Villamayor, M.M.S.; Keraudy, J.; Shimizu, T.; Viloan, R.P.B.; Boyd, R.; Lundin, D.; Greene, J.E.; Petrov, I.; Helmersson, U. Low temperature ( $\mathrm{Ts} / \mathrm{Tm}<0.1)$ epitaxial growth of $\mathrm{HfN} / \mathrm{MgO}(001)$ via reactive HiPIMS with metal-ion synchronized substrate bias. J. Vac. Sci. Technol. A 2018, 36, 061511.

40. Seo, H.S.; Lee, T.Y.; Wen, J.G.; Petrov, I.; Greene, J.E.; Gall, D. Growth and physical properties of epitaxial HfN layers on $\mathrm{MgO}(001)$. J. Appl. Phys. 2004, 96, 878-884. [CrossRef]

41. International Center for Diffraction Data: Card No. 45-0946; ICDD: Newtown Square, PA, USA.

42. Oliveira, J.C.; Ferreira, F.; Anders, A.; Cavaleiro, A. Reduced atomic shadowing in HiPIMS: Role of the thermalized metal ions. Appl. Surf. Sci. 2018, 433, 934-944. [CrossRef]

43. Nieuwenhuizen, J.M.; Haanstra, H.B. Microfractography of thin films. Philips Tech. Rev. 1966, $27,87-91$.

44. Tait, R.; Smy, T.; Brett, M. Modeling and Characterization of Columnar Growth in Evaporated-Films. Thin Solid'Films 1993, 226, 196-201. [CrossRef]

45. Zhu, H.; Cao, W.; Larsen, G.K.; Toole, R.; Zhao, Y. Tilting angle of nanocolumnar films fabricated by oblique angle deposition. J. Vac. Sci. Technol. B 2012, 30, 030606. [CrossRef]

46. Alvarez, R.; Lopez-Santos, C.; Parra-Barranco, J.; Rico, V.; Barranco, A.; Cotrino, J.; Gonzalez-Elipe, A.R.; Palmero, A. Nanocolumnar growth of thin films deposited at oblique angles: Beyond the tangent rule. J. Vac. Sci. Technol. B Nanotechnol. Microelectron. Mater. Process. Meas. Phenom. 2014, 32, 041802. [CrossRef]

47. Shetty, A.R.; Karimi, A. Texture mechanisms and microstructure of biaxial thin films grown by oblique angle deposition. Phys. Status Solidi Basic Res. 2012, 249, 1531-1540. [CrossRef]

48. Van der Drift, A. Evolutionary Selection, a principle governing growth orientation. Philips Res. Rep. $1967,22,267-288$.

49. Elofsson, V.; Saraiva, M.; Boyd, R.D.; Sarakinos, K. Double in-plane alignment in biaxially textured thin films. Appl. Phys. Lett. 2014, 105, 233113. [CrossRef]

50. Holec, D.; Friák, M.; Neugebauer, J.; Mayrhofer, P.H. Trends in the elastic response of binary early transition metal nitrides. Phys. Rev. B 2012, 85, 064101. [CrossRef]

51. Chen, X.J.; Struzhkin, V.V.; Wu, Z.; Somayazulu, M.; Qian, J.; Kung, S.; Christensen, A.N.; Zhao, Y.; Cohen, R.E.; Mao, H.K.; et al. Hard superconducting nitrides. Proc. Natl. Acad. Sci. USA 2005, 102, 3198-3201. [CrossRef]

52. Windischmann, H. Intrinsic stress in sputter-deposited thin films. Crit. Rev. Solid State Mater. Sci. 1992, 17, 547-596. [CrossRef]

53. Janssen, G.C.A.M. Stress and strain in polycrystalline thin films. Thin Solid Films 2007, 515, 6654-6664. [CrossRef]

54. Magnfält, D.; Abadias, G.; Sarakinos, K. Atom insertion into grain boundaries and stress generation in physically vapor deposited films. Appl. Phys. Lett. 2013, 103, 051910. [CrossRef]

55. Chason, E.; Karlson, M.; Colin, J.J.J.; Magnfält, D.; Sarakinos, K.; Abadias, G. A kinetic model for stress generation in thin films grown from energetic vapor fluxes. J. Appl. Phys. 2016, 119, 145307. [CrossRef]

56. Abadias, G.; Guerin, P. In situ stress evolution during magnetron sputtering of transition metal nitride thin films. Appl. Phys. Lett. 2008, 93, 111908. [CrossRef]

57. Abadias, G.; Leroy, W.P.; Mahieu, S.; Depla, D. Influence of particle and energy flux on stress and texture development in magnetron sputtered TiN films. J. Phys. D Appl. Phys. 2013, 46, 055301. [CrossRef]

58. Abadias, G.; Koutsokeras, L.E.; Siozios, A.; Patsalas, P. Stress, phase stability and oxidation resistance of ternary Ti-Me-N (Me = Zr, Ta) hard coatings. Thin Solid Films 2013, 538, 56-70. [CrossRef]

59. Jaing, C.; Liu, M.; Lee, C.; Cho, W.; Shen, W.; Tang, C.; Liao, B. Residual stress in obliquely deposited $\mathrm{MgF}_{2}$ thin films. Appl. Opt. 2008, 47, 266-270. [CrossRef]

60. Yu, H.Z.; Thompson, C.V. Effects of oblique-angle deposition on intrinsic stress evolution during polycrystalline film growth. Acta Mater. 2014, 77, 284-293. [CrossRef]

(C) 2019 by the authors. Licensee MDPI, Basel, Switzerland. This article is an open access article distributed under the terms and conditions of the Creative Commons Attribution (CC BY) license (http://creativecommons.org/licenses/by/4.0/). 